\title{
UNDERHILL MOORE'S LEGAL SCIENCE: ITS NATURE AND SIGNIFICANCE
}

\section{F. S. C. NORTHROP†}

THE legal science of Underhill Moore was the product of the two major movements of modern legal thought: legal realism and sociological jurisprudence. It demonstrates both the strength and the limitations of these two legal theories. His work had this somewhat paradoxical character because he substituted scientifically exact methods and deeds for the vivid but unverifiable, pseudo-descriptive prose in which these two movements had all too often been previously expressed. When this was done the actual capability of a legal science grounded in a realistic application of scientific methods to social and legal facts was revealed to be quite different from what many earlier proponents had claimed. Consequently, more than anyone else Underhill Moore demonstrated precisely what legal realism and sociological jurisprudence as traditionally conceived can and cannot do. And for this reason his work probably marks not merely the culmination of the jurisprudence of the recent past but also a turning point in legal science generally. It is as important, therefore, as a clue to the legal science of the immediate future as it is to an estimation of the remarkable original contributions of Underhill Moore to legal and social science that we become clear about the aim, the method and the results of the unique sociology of law which he created and applied.

The aim and the method of Underhill Moore's legal science are inseparable. This is the case because his aim was to provide legal realism and sociological jurisprudence with a rigorous scientific method. Thereby he hoped to achieve at least the beginnings of a dependable legal science adequate to the changing and novel legal and social problems of our time.

The method which he chose was that of natural science applied to social and legal facts. In making this choice he was but following the generally accepted claim of most legal realists and social scientists. ${ }^{1}$ The general conception was that the traditional legal and social sciences were inadequate because previous thinkers had trusted to formal logic applied to the abstract nouns of propositions purporting to describe "the law." This situation, they thought, would be put right when legal and social scientists became realistic and scientific about the concrete facts and concrete changing systems of their subject-matter in the

† Sterling Professor of Philosophy and Law, Yale Law School.

The author is indebted to the Viking Fund for a grant which made this and other research in this field possible.

1. Some legal realists, such as Professor Karl N. Llewellyn, never claimed that legal realism could resolve normative problems in law. 
same manner that the natural scientists had become realistic and scientific with respect to theirs. For example, Ehrlich in his chapter on "The Methods of the Sociology of Law" wrote: "And sociology . . . , including the sociology of law must be a science of observation." 2

Little, however, did the legal realists and sociological jurists realize what they were being let in for when Underhill Moore took them thus at their word. For Underhill Moore was not so naive as to suppose that everyone knows what the methods of natural science are. $\mathrm{He}$ refused to indulge in the vivid extemporized prose of a Thurman Arnold or the intuitive literary description of a Veblen. And much as he admired the aim of the sociological jurisprudence of Ehrlich and Pound, he became suspicious of their method because of its too frequent reliance on books about past societies rather than direct observation of a present one.

The two-fold program which Underhill Moore launched at first amused his fellow realists and sociological jurists, impressing them as trivial. But when its import became more evident, it struck them as almost a betrayal of his professional class. First, he made a study of the specific methods of natural science to find out what they were when successful as with Galilei and Newton. Then he applied these specific methods, not to the unobservable ancient Greeks and Romans, or to the equally unobservable inner urges of present judges in courts of lower jurisdiction, or even to the sex life of distant contemporary savages, but to the social and legal behavior of human beings in the New Haven community whom he and his colleagues could see with their own eyes. If, as sociological jurisprudence asserts, law is to find its basis in social science, then, said he, in deed as well as in word, we must be sure that the methods of this sociology of law are scientific. And he added, if jurisprudence is to be realistic, let its realism be that of plain concrete social and legal facts which are right before our eyes and which anyone can get at. One of the ways in which he put this view into practice was to make a rigorously objective observation of car parking and traffic under police regulations on specific, carefully selected streets and street intersections a few blocks from the Yale Law School in New Haven, Connecticut.

There was more even than straight-forward common sense behind this approach. He had not studied and reflected upon the specific procedure of Galilei and Newton in natural science to no avail. Galilei founded modern physics by beginning with the simplest case he could find, namely, a ball let fall freely from one's hand to the floor. Nevertheless, by his study of this simplest case of mechanical motion, Galilei discovered and later, in the famous inclined plane experiment, verified the basic concept of force upon which modern physics rests and from

2. Ehrlich, Fundamental Princtples of the Sociology of Law 473 (1936). 
which Newton's two universal laws governing all mechanical motion, however complicated, derive. ${ }^{3}$ Furthermore, by the formal logical methods of deductively formulated scientific theory, Newton in his famous Principia proved that with slight additions and generalizations the basic concepts and universal principles which Galilei discovered through the study of a commonplace simple motion were able to account for the complicated motions not merely of the projectile and the pendulum but also of the gyroscope and even of the stars and planets in their courses. Moreover, Ehrlich in his specification of the methods of sociological jurisprudence held up the economic science of BoehmBawerk as a model and noted favorably that it is deductively formulated and based upon facts "from common everyday life as it presents itself to every one of us." 4 "Thus, instead of pursuing the trivial in his studies of commonplace social phenomena, Underhill Moore was following the very method prescribed by one of the main founders of the sociology of law. It is in simple situations often that one finds the key factors and relations of a science.

Having reflected on facts such as these Underhill Moore knew that this was a sound procedure for a lasting solution of even the wider national and international social and legal questions which absorbed the interest of his colleagues. It was by no means trivial to seek, by observations and experiments repeatable by anybody, for the key concepts and principles involved in the simplest and most commonplace instance of a socio-legal phenomenon he could find. Hence, his parking and traffic studies.

Underhill Moore's study of the specific method of natural science made him aware of one other fact. Every empirical natural science passes through two stages involving quite different scientific methods. The first stage is appropriately called the natural history stage; the second, the stage of deductively formulated, indirectly and experimentally verified theory. The excessively inductive, largely descriptive physics of Aristotle illustrates the first stage. The deductively formulated, indirectly and experimentally verified physics of Newton's Principia illustrates the second stage. ${ }^{5}$

In the early natural history stage of an empirical science the premium is upon determining the facts of one's subject-matter. Hence the scientific methods of this stage are the inductive methods of observation, description and classification, where the concepts used in the description and classification get their meanings denotatively and inductively from directly observable entities and properties. To these methods there is added in this stage the methods formulated by Mill

3. Mach, The Science of Mechanics 30 et seq. (1919).

4. EHRLICH, op. cit. supra note 2, at 473.

5. Cf. Northrop, The Logic of the Sciences and the Humanities, cc. III, IV, VI (1947). 
for determining piecemeal, causal sequence of the type described by Hume and illustrated in the common sense experience of lightning and thunder. The science of this earlier natural history stage is necessary as a preliminary for further advance and is reasonably adequate descriptively; but precisely for this reason it merely tells us what the facts are without giving the general basic concepts and universal principles in terms of which they can be understood and systematically related. Furthermore, it lacks systematic or structural predictive power from the present to the future. It is to overcome these weaknesses that natural science passes on from the descriptive inductive methods of the natural history stage to the deductive and experimental methods of indirectly verified, deductively formulated theory. ${ }^{6}$

By the systematic or structural predictive power mentioned above, which experimentally verified, deductively formulated scientific theory alone makes possible but does not guarantee, is meant a predictive power such as occurs in the deductively formulated physics of Newton, Maxwell, Einstein or Schrödinger. In such a scientific theory a few basic concepts designating independent variables define the structure which is the state of the system at any time in such a way that given the postulates of the theory and the operational definitions which permit today's empirical values of the independent variables to be determined, the empirical values defining the structure of the system at any specified time in the future can be deduced. ${ }^{7}$ It is to be noted that predictive power of this systematic structural type, which only experimentally verified, deductively formulated scientific theory is capable of giving, is quite different from either (a) the relatively weak extrapolation into the future of inductively gathered empirical curves illustrated in Gallup poll statistics, or (b) the piecemeal predictive power of Mill's inductive methods, both of which belong to the natural history stage of empirical science. As the physicist Henry Margenau has written, "Causality [is] not . . . a regularity describing sense impressions or inherent in them. . . . Ordinary mechanics would not be a causal theory if states were defined in terms of color and sizes. ... To speak of sensed nature as being causal or noncausal has no significance whatever. . . . Causality therefore has meaning only when applied to . . . theories." 8

It has been necessary to go into these methodological distinctions

6. Id. at 116.

7. Cf. Lindsay \& Margenau, Foundations of Physics 99 and c. X (1936); Margenau, Meaning and Scientific Status of Causality, 1 Philosophy of Science 133 (1934); Northrop, The Logic of the Sciences and the Humanities, c. XII (1947).

8. Metaphysical Elements in Physics, 13 Reviews of Modern Physics, 177, 187 (1941). See also Northrop, The Logic of the Sciences and the Humanities (1947) ; Lasswell \& McDougal, Legal Education and Public Policy: Professional Training in the Public Interest, 52 Yale L. J. 203-95 (1943). 
because otherwise neither the importance of, nor the scientific reasons for Underhill Moore's specific method in legal and social science can be understood. Nor will one appreciate the difficulties and the probably insuperable limitations of a legal realism or sociological jurisprudence which restricts itself to the application of even the most effective methods of natural science to social and legal facts. The heart of the matter can be put as follows: A legal realism and sociological jurisprudence which is adequate to the social and legal needs of the contemporary world must be one which can adjudicate between conflicting present economic, political, social and legal norms and also specify a scientifically verified new norm. For certainly the basic social and legal problems of the contemporary world, domestic as well as international, are inescapably ideological and normative in character. Different nations have different social and legal codes. Also, within any nation the old codes are proving to be inadequate for resolving the inescapable problems of an increasingly technological society in an atomic age. A legal science which is of any positive use must be able to specify new norms to replace the old. Such a legal realism and sociological jurisprudence must be one which has systematic or structural predictive power from the present state of society to the future. The piecemeal predictive power of Mill's inductive methods and of inductively gathered statistical curves extrapolated into the future will not do for the reason that, according to sociological jurisprudence, legal codes and social norms when effective must reflect what Ehrlich called "the inner order," " 9 and what Underhill Moore termed "the group habits" 10 or "the high frequency behavior" of men in society. ${ }^{11}$ This means that legal and social norms have their basis, according to sociological jurisprudence, not in any piecemeal factor but in the systematic relational or structural factor in society. ${ }^{12}$ Consequently, only a legal and social science which has systematic or structural predictive power from today's "inner order of society" to tomorrow's, can give today the new norms necessary to replace the outmoded and crumbling legal codes and norms of the present status quo. This only an experimentally verified, deductively formulated social and legal science has the possibility, even though not the guarantee, of doing. Hence an adequate social science and sociological jurisprudence must be of this type. It was the genius of Underhill Moore to have seen this and to have gone about the

9. EhrLICH, op. cit. supra note 2, at cc. II, III.

10. Moore, Rational Basis of Legal Institutions, 23 CoL. L. REv. 609, 613 (1923).

11. Moore \& Hope, An Institutional Approach to the Law of Commercial Banking, 38 Yale L.J. 703, 705 (1929).

12. Even in 1929 in the imperfect initial formulation of the method of his legal science, Underhill Moore in conjunction with Theodore S. Hope, Jr. wrote: "The subject of the proposed study is human behavior. The study proposed is a systematic study." Moore \& Hope, supra note 11 , at 705. 
unconventional and painstaking, laborious task of attempting to achieve it. The beginnings were made in 1929 in a preliminary way in what he termed "the choice and logical elaboration of categories and sub-categories," 13 and carried forward on more rigorous foundations through 1943 when he completed his final great work in conjunction with Charles C. Callahan. ${ }^{14}$

He had found when he turned to sociology that no such deductively formulated sociology existed. Existing sociology is still for the most part in the inductive, descriptive, Gallup poll statistics, natural history stage. The last attempt at a deductively formulated, experimental sociology was made by Pareto. ${ }^{15}$ It ended in failure because too many of Pareto's key variables were located, after the manner of the inner urges of the judges of gastronomical jurisprudence and of Freudian psychology, in the inner instincts and introspective interiors of the ancient Greeks and Romans or of contemporary American magistrates where no one could determine whether they existed or not. ${ }^{16}$ Hence, Underhill Moore had no alternative but to attempt the foundation of a new experimentally verified, deductively formulated sociology as well as a new sociology of law. For this reason his work is as novel and important for sociologists generally as it is for students of law.

To be aware of the aforementioned causes of the failure of Pareto's sociology and the similar weakness of gastronomical jurisprudence is to understand why Underhill Moore chose the basic concepts and postulates of the behavioristic psychology of his Yale colleague, Professor Clark Hull, ${ }^{17}$ as the basis for his new social and legal science. Being behavioristic it provided propositions capable of verification by observable operations which were repeatable by anyone. Imaginative speculations about the inner urges and frustrations of judges were no longer necessary. It also avoided the intuitive judgments which the earlier method of his commercial banking studies was found to entail. ${ }^{18}$ Moreover, the psychology of Professor Hull offered another advantage. It provided a generalization of the assumptions of the earlier behaviorism which permitted an inclusion of the verifiable portion of the very suggestive Freudian theory. And most important of all this psychology was not merely indirectly and experimentally verifiable

13. Id. at $705-6$.

14. Moore \& Callahan, Law and Learning Theory: A Study in Legal Control, 53 YALE L.J. 1 (1944).

15. Pareto, Traité de Sociologie Générale (1917). For English translation from the later Italian edition (1923) see 1 Pareto, The Mind and Society (Livingston's ed. 1935).

16. See Northrop, The Logic of the Sciences and the Humanities, c. XV (1947).

17. Hull, Principles of Behavior (1943).

18. Moore \& Hope, supra note 11, at 719; Moore \& Sussman, Legal and Institutional Methods Applied to the Debiting of Direct Discounts-II: Institutional Method, 40 YaLE L. J. 555, 1220-21 and especially 1228-32 (1932). 
but also deductively formulated. ${ }^{19}$ In fact the deductive formulation was rigorous, having been done in considerable part in the exact symbolism of mathematical logic by Professor Frederic B. Fitch. ${ }^{20}$ This gave Underhill Moore's social and legal science precisely the methodological character and content which were needed. He had a scientific method which was objective and which had the deductively formulated character which is the necessary if not the sufficient condition for the prediction of the future living law and the new norms or positive law corresponding to it.

This happy good fortune was not the arbitrary result of local circumstances. There are reasons quite apart from the recourses of the Yale community in Underhill Moore's time for choosing psychological concepts as the basis of social and legal theory. Society is the product of the activity of human beings. Also modern neo-classical economic science of the Austrian school is deductively formulated and its concepts are those of psychology derived from the British empirical philosophy of Hume and Bentham. And as was noted previously, it was precisely this particular economic science which Ehrlich set as a model for the sociology of law.

One assumption of Underhill Moore's legal science, as built upon Professor Hull's behavioristic psychology, is very important: namely, that all legal and social behavior is a response to a stimulus only and never the response to the meaning of the cue or mark which is the stimulus. "A proposition of law," he and Professor Callahan wrote, "is nothing more than a sensible object which may arouse a drive and cue a response." ${ }^{21}$ This assumption also explains in part, but, as we shall see shortly, only in part, why a "distinguished authority on Bills and Notes" is described by Professors Lasswell and McDougal as insisting that "a teacher who expresses a social preference in the classroom should be fired." ${ }^{22}$ If meanings have no part in legal and social science, then meaningfully and symbolically designated norms and preferences for such norms should have no place in the discourse of a professor of legal science.

The point of the latter conclusion is not that Underhill Moore supposed social and legal problems could be solved without assumptions concerning norms or values. He had the most serious interest in the attempt of the present writer to specify ${ }^{23}$ and apply ${ }^{24}$ the new method,

19. Hull, Hovland, Ross, Hall, Perkins \& Fitch, Mathematico-Deductive THEORY OF ROTE LEARNing (1940).

20. Id. at 309-26. Recently Professor Fitch and Gladys Berry obtained a more complete formulation, Towards a Formalization of Hull's Behavior Theory, to be published in Philosophy of Science (summer, 1950).

21. Moore \& Callahan, supra note 14 , at 3 .

22. Lasswell \& McDougal, supra note 8, at 205 n. 7.

23. Northrop, The Logic of the Sciences and the Humanities, c. XXI (1947); Northrop, Jurisprudence in the Law School Curriculum, 1 J. LEg. ED. 482 (1949).

24. Northrop, The Meeting of EAst and West (1946). See also Pound, Toward 
supplementing the methods of traditional legal realism and sociological jurisprudence, for determining social norms and solving normative social and legal problems. In fact, his own research convinced him, as it was instrumental in convincing me, of the necessity of a new method in social and legal science if those disciplines are to resolve their normative problems. The point, therefore, of his prohibition upon professors expressing preferences in the classroom was that until one actually possesses a method, such as the aforementioned, for determining new specific norms, as he knew very well Thomism, neo-Kantianism, neoHegelianism, legal realism and sociological jurisprudence did not possess, such legal teachers must be honest about what their legal methods and theories permit them to do. They must not in the name of legal realism or sociological jurisprudence give expression to normative preferences to which the methods of these or any other of the traditional conceptions of legal and social science do not entitle one.

Why did Underhill Moore conclude that the methods of legal realism and sociological jurisprudence, in which he so thoroughly believed, were incapable of resolving normative social and legal problems? To answer this question, the following considerations must be clearly grasped. According to sociological jurisprudence, the ethical and legal norms for solving the disputes of society have their basis in, and if effective must correspond to, the de facto "inner order of society." ${ }_{25}$ This seems to provide a definite criterion for determining norms by the realistic sociological method. Actually, however, as Underhill Moore noted, it is as vacuous as the abstract nouns of the Austinian analytic jurisprudence, unless objectively valid specific operations or methods by which "the inner order of society" is to be determined are made explicit. That this had not been done becomes evident the moment one asks the question: How does the lawyer advising his client, or the judge making his decision, determine what "the living law" inner order of the de facto society is?

The previous legal realism and sociological jurisprudence had tended to assume that one had but to recognize and direct one's attention toward the realistic sociological basis of legal norms to know what the de facto inner order of society is. As Underhill Moore put it, the judge or lawyer determined the inner order or high frequency institutional behavior of society by a single essentially introspective, intuitive judgment. Through a vague cultural osmosis the de facto social order was assumed to register itself in the introspective consciousness of the legally realistic judge or sociologically minded jurist. But the reliability of introspective intuitive judgments as a criterion of social objectivity is entirely too questionable to be taken as a scientific basis

a New Jus Gentium; Kluckhohn, The Philosophy of the Navaho Indians; Sorokin, Lasting and Dying Factors in the World's Cultures; Dorsey, Two Objective Bases for a Legal World Order; all in Ideological Differences and World Order (Northrop ed. 1949).

25. EHRICH, op. cit. supra note 2. 
for legal science. Introspective intuitive judgments of objective public facts are notoriously relativistic and untrustworthy. Clearly a legal realism or sociological jurisprudence, whose explicit method for determining the objective inner order of society is impressionistic, introspectively subjective and intuitive, is just as spurious in its objectivity as is gastronomical jurisprudence or the appeal to the undefined abstract nouns of the Austinian analytic jurisprudence.

It follows, therefore, that if legal realists and sociological jurists are themselves to escape the subjective arbitrariness against which they protest when it occurs in the Austinian analytical jurisprudence, they must be given a more objective method for determining the inner order of society. Or at the very least the trustworthiness of an introspective, impressionistic, intuitive method must be established by a check against the objective evidence.

It was this objective check which the method introduced in Underhill Moore's field studies of commercial banking was designed to provide. However, after applying this more objective method two things became evident: First, notwithstanding its careful "elaboration of categories" and laborious gathering of data, this new method had merely broken up the one gross, essentially introspective, intuitive judgment into thirteen different similarly introspective intuitive judgments. Second, when he gave the objective data to experts in a bank on the one hand and to himself and his co-workers on the other hand and asked these two groups to make the thirteen intuitive judgments, there was in one case a difference of conclusion for four of the thirteen judgments. ${ }^{26}$ In short, even when supplemented with objective data and applied to a very simple social situation, the method of intuitive judgments in legal realism and sociological jurisprudence is not a trustworthy means of determining the inner order of society. This conclusion becomes even more inescapable when it is noted that these intuitive judgments were made not by distant judges on the bench but by bankers and social scientists intimately acquainted with the social institutions they were judging.

Underhill Moore was forced, therefore, to conclude that the method of legal science must drop introspective, intuitive judgments and become completely objective. In short, legal science must base itself upon behavioristic rather than introspective psychology.

It does not follow from this, as so many critics have concluded erroneously, that Underhill Moore's legal science and behavioristic psychology are invalid because they deny the existence of introspected impressions and the scientific validity of the introspective method. Underhill Moore, like Professor Hull, grants the scientific validity of introspective methods to give what they can give, namely subjective

26. Moore \& Sussman, supra note 18 , at 1231 n. 35 . 
data and impressions. He affirms also that in some instances one's introspected impressions of the character of the objective social order correspond to that objective order. But he recognizes also, as must everyone else, that in many cases, and as his bank credit studies demonstrate, even in very simple cases, one's introspected subjective impressions of the objective social order do not correspond to the objective order itself. In short, introspective psychological methods can give scientifically valid knowledge concerning what impressions a judge or jurist has of the objective inner order of society; they cannot, however, give scientifically valid knowledge of whether one's introspected subjective impression corresponds to the objective social order to which it purports to refer.

To determine the objective social order itself and whether the latter order corresponds to one's subjective impression of it, the methods of behavioristic psychology are required. Since sociological jurisprudence would ground law not in the subjective introspection of what the judge or jurist believes the inner order of society to be but in the objective order itself, it follows, as Underhill Moore saw, that its method must be that of behavioristic rather than of merely introspective psychology.

When, however, such a behavioristically grounded, completely objective method for legal science was constructed and applied by Underhill Moore in his traffic and parking studies, two things happened with respect to the capacity of legal realism and sociological jurisprudence to formulate or resolve normative legal and social problems. These two results must be grasped if his judgment concerning normative preferences by professors of law is to be understood.

First, the acceptance of behaviorism and a completely objective method enforced the aforementioned thesis that "a proposition of law is nothing more than a sensible object which may arouse a drive and cue a response." This conclusion follows because the meaning of a sign or symbol considered as the cue to a response is knowable directly only by introspection. Hence, if introspective judgments are to be avoided in the determination of the objective social order itself, then the sign, or the proposition of law which is a group of signs, must be treated merely as a particular stimulus and never as the meaning of the sign or stimulus.

This makes it very difficult even to formulate legal and social norms which have not yet issued in overt observable behavior. Legal realism and sociological jurisprudence thus find themselves confronted with a paradox with respect to norms. When these two theories of legal science use the introspective, intuitive method, they become as arbitrary, subjective, relativistic and untrustworthy as the Austinian jurisprudence which they condemn; in short all the reasons which legal realists and sociological jurists give for rejecting the Austinian analytic 
jurisprudence hold against them also. When on the other hand they become completely objective, as occurs in the method of Underhill Moore's Law and Learning Theory, the normative propositions of legal and social science are bereft of all meaning and function merely as stimuli. In short, although one obtains objectivity, the objectivity is that of a bare particular stimulus bereft of all meaning.

Since Professor Clark Hull's behavioristic psychology was formulated, two very important developments have occurred in neurological science and behavioristic psychology. The first is the demonstration by Doctors Warren McCulloch and Walter Pitts ${ }^{27}$ that the central nervous system of any man is so constructed that stimuli must be trapped in the form of preserved impulses passed around a circular neural net and that these persisting impulses representing past stimuli are the formal equivalent of universals or meanings. Furthermore, these representatives of meanings may fire motor neurons. In short, contemporary neurological science enforces the conclusion that human behavior is a response not merely to stimuli but also to the particular set of trapped representatives ${ }^{28}$ of universals which the individual has selected to account for all the facts, i.e., stimuli, of his experience. In this sense, therefore, human behavior is a response to the equivalents of universals and hence a response to meanings; it is not as Underhill Moore assumed a mere response to stimuli. Professors Arturo Rosenblueth, Norbert Wiener and Julian Bigelow have also shown ${ }^{29}$ that a behavioristic mechanical system, providing it has a certain structure which only certain mechanical systems possess, must be a teleologically acting system. They have demonstrated, in addition, that the central nervous systems of all men possess this structure. Thus contemporary behavioristic psychology requires that all human beings be conceived as teleological systems.

Both of the foregoing, scientific discoveries entail a modification in Underhill Moore's legal science. The work by Professors McCulloch and Pitts demonstrates that a legal science grounded in a neurological psychology, the method of which is completely objective, can account for meanings. The work of Professors Rosenblueth, Wiener and Bigelow demonstrates that behavioristic psychology in connection with such a neurology can also account for the purposeful or teleological activity of men.

27. Northrop, Ideological Man in His Relation to Scientifically Knozen Natural Man in Ideological Differences and World Order 407 (Northrop ed. 1949); see also

$\rightarrow$ Rosenblueth, Wiener \& Bigelow, Behavior, Purpose and Teleology, 10 Philos. of ScIENCE 18-24 (1943); Wiener, Cybernetics (1948).

28. To avoid confusing worlds of discourse, the relation between a "universal" in its introspected manifestation and a "universal" in the discourse of neurology must be specified. It seems appropriate to call this relation "epistemic correlation." See Northrop, ThE Logic of the Sciences and the Humanities, c. VII (1947).

29. See note 27 supra. 
This writer has suggested ${ }^{30}$ that the goal in the teleologically acting human being may in certain instances be a group of the aforementioned equivalents of meanings or universals, and that when this occurs the behavior will be guided by ideological factors. Modification of Underhill Moore's legal science, therefore, in these three directions, as required by contemporary developments in behavioristic and neurological psychology, will overcome its aforementioned weakness with respect to the statement of norms and their significance in human and social behavior.

Notwithstanding the foregoing limitations of Underhill Moore's thesis that a proposition in law is merely a stimulus or cue to a response, this assumption was not without its significance in his research. For even with this very weak assumption, his studies do unequivocally demonstrate that normative propositions and beliefs, such as a proposition of law, make a difference in the high frequency, living law behavior of men in society. The difference in the distributions of parked cars before and after a normative legal symbol has been introduced shows this conclusively. The fact that in Underhill Moore's method the proposition of law is taken in the weakest sense possible as mere stimulus makes this result of his work all the more conclusive.

The latter finding may seem to many people to be very trivial. Some have said that everyone knows this without all the labor of Underhill Moore's carefully controlled observations. Such a conclusion overlooks the fact, however, that many social scientists and countless laymen who follow current fashions in social science assert that norms and ideas merely reflect and propositionalize social facts after the event and in no way make social facts even in part what they are. Underhill Moore's findings, even on his unnecessarily weak assumption concerning the nature of a proposition of law, unequivocally give the lie to this prevalent notion.

Nevertheless, even with the aforementioned required modifications in the basic psychological assumption of Underhill Moore's legal science, it is by no means evident that legal realism and sociological jurisprudence are thereby rendered adequate to the social and legal needs and problems of our time. This brings us to the second consequence of his research with respect to the specification of legal and social norms. This consequence had its basis in his empirical findings. Hence it is likely to characterize any legal realism or sociological jurisprudence.

The weakness becomes evident when one turns from the problem of an objective method for determining today's de facto inner order of society and its corresponding positive law norms to the question of determining new norms to replace the present ones. It is to be em-

30. See note 27 supra. 
phasized, as Underhill Moore was very well aware, that the basic domestic, international and legal problems of our times are of the latter character. The contemporary world is characterized by the diversity of normative social and legal theories competing for the minds of men. The most vital disputes of our world are raising questions about whether one norm or another should be used to decide the dispute. Furthermore, technological discoveries, such as the method for releasing atomic energy, are rendering many present social and legal norms inadequate if not obsolete. ${ }^{31}$ The crucial test for legal realism and sociological jurisprudence comes, therefore, when we ask the question: Does this conception of legal science provide a method for determining the new norms to replace the old? Underhill Moore's research demonstrated that this question must be answered in the negative.

The difficulty centers in predictive power. According to sociological jurisprudence, the correct normative propositions of positive law are those which correspond to the high frequency behavior, or what Ehrlich termed the living law, of de facto society. Providing, as Underhill Moore's final method for legal science assures, one can obtain an objective determination of the high frequency behavior, or living law, of de facto society, sociological jurisprudence does provide a definite objective criterion of positive legal norms for the social status quo. Suppose, however, as is the case at present, not merely the positive law but also the underlying living law of the status quo is in question. Can sociological jurisprudence designate the new legal and social norms for judging and changing the high frequency behavior or living law of today's status quo? The answer is in the affirmative providing sociological jurisprudence has a scientific method and attendantly verified, deductively formulated theory which is such that given an objective determination of today's high frequency behavior or inner order of society it cannot ambiguously deduce tomorrow's. Given such a capacity today to deduce or predict tomorrow's living law, the sociological jurist would then merely have to write out the positive law norms corresponding to tomorrow's predicted living law to possess today the new legal norms for judging and instrumentally transforming not merely the positive law but also the living law of today's status quo.

The following graph represents the situation:

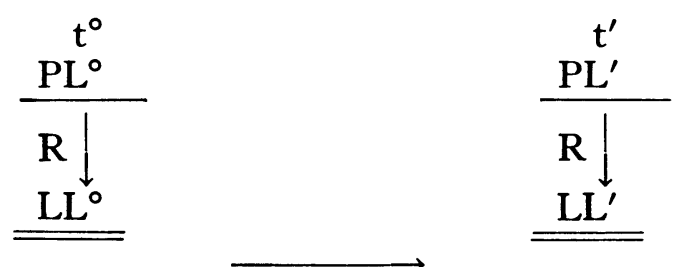

Time direction

31. Northrop, Jurisprudence in the Lawe School Curriculum, 1 J. LEG. Ed. 482 (1949). 
where $t^{\circ}=$ the present state of the social system

$\mathrm{t}^{\prime}=\mathrm{a}$ future state of the social system

$\mathrm{PL}=$ the normative propositions of positive law

$\mathrm{LL}=$ the living law or high frequency behavior of de facto society

$\mathrm{R}=$ the relation of correspondence between the correct positive legal norm and the de facto living law.

If, given an objective determination of $\mathrm{LL}^{\circ}$ at the present time $t^{\circ}$, one's empirically verified legal science enables one to deduce $L L^{\prime}$ at the future time $t^{\prime}$, then sociological jurisprudence would, by merely writing out $\mathrm{PL}^{\prime}$ in correspondence with the deduced $\mathrm{LL}^{\prime}$, possess a method for specifying the new legal and social norm to replace the old. Moreover, precisely because $\mathrm{PL}^{\prime}$ as thus knowable at the present time $t^{\circ}$ corresponds to a living law not yet reached in de facto society, it avoids the culturalistic fallacy ${ }^{32}$ of identifying the "ought" for today's society with its "is." Hence, if achieved at the present time $t^{\circ}, \mathrm{PL}^{\prime}$ would provide a normative criterion for changing not merely the positive law but also the living law and social and legal institutions of the present status quo.

It was precisely this predictive power of $\mathrm{PL}^{\prime}$ by way of the prediction of $\mathrm{LL}^{\prime}$ for which Underhill Moore was seeking. Again and again he asserted that the basic problem of legal practice and legal science is the problem of prediction. ${ }^{33}$ Considerations such as the foregoing made him acutely aware that unless he obtained a present prediction of the future living law, legal realism and sociological jurisprudence must, if they are scientifically honest, remain perpetually silent on normative issues. Without a legal science which predicts tomorrow's high frequency order of society from today's, legal realism, sociological jurisprudence and social science generally can say nothing about the new social and legal norm required to meet the new domestic and international social problems for which the existing social practices and the present codified legal norms are inadequate. It can merely record and echo the positive law norms which correspond to the present social status quo.

It has been noted earlier in this paper that a necessary condition for such predictive power is not merely that legal science must use an objective method but also that it must have a deductively formulated theory. It was noted also, however, that his necessary condition, which Underhill Moore's final formulation of legal science met, is not a sufficient condition for predictive power. Modern economic science is deductively formulated yet it does not achieve this type of predictive

32. Northrop, The Meeting of EAst and West, 212-3, $255-9$ (1946), and Northrop, The Logic of the Sciences and the Humanities, 70, 279 et. seq. (1947).

33. Moore \& Hope, supra note 11, at 719; Moore \& Sussman, The Lawyer's Laze, 41 YALE L.J. 566 (1932). 
power. ${ }^{34}$ Consequently the mere fact that Underhill Moore achieved an objectively verifiable, deductively formulated sociology of law is not a guarantee that such a sociological jurisprudence will obtain the time-equation connecting $\mathrm{LL}^{\circ}$, the present inner order of society, to $\mathrm{LL}^{\prime}$, the deducible future inner order of society, which is necessary if sociological jurisprudence is to provide any criterion of new legal codes and norms to replace the old.

Underhill Moore found at the end that the application of his method failed to permit the deduction of tomorrow's living law from today's. The evidence for this conclusion came out in the following way. In his parking studies he made an objective determination of the distribution of parked cars in a given area before a given positive law regulation was posted. He then made a similar determination of the parking distribution after the positive law proposition or regulation had been posted. All this was done under conditions which were otherwise similar in the two cases. At first sight the very design of the experiment seems to rule out any possibility of the determination of new norms. The experiment seemed to be testing nothing more than the change in the living law distribution with the introduction of a new positive law symbol. His experiments can be looked at from this standpoint, and do, as noted above, give a positive answer to the question as to whether the introduction of new positive law alters the living law. The experiment can, however, be looked at in another way and used to answer a different type of question. In any single study, the two curves representing the different distribution of parking before and after the posted regulation represent two different living laws. One, the living law, $L L^{\circ}$ at the earlier time $t^{\circ}$; the other the living law $L L^{\prime}$ at the later time $t^{\prime}$. If, therefore, by studying the relation between these two curves one could find an equation holding for many different similar studies, relating the first curve to the second, then one could have the aforementioned time-equation which would make it possible, if given an objective determination of the $\mathrm{LL}^{\circ}$ living law of the present, to deduce the $\mathrm{LL}^{\prime}$ living law of the future.

In this connection Underhill Moore's assumption that the propositions of the positive law function merely as stimuli and not as meanings was an asset rather than a liability. This assumption permitted him to treat the positive law symbols merely as one instance of any stimulus in a society which might have the effect of changing the structure of present society into that of the society of the immediate future. Then his experiment became a study in the relation joining the living law at one time to the living law of the same social system at a later time.

In seeking for the mathematical formula connecting today's living law to tomorrow's, Underhill Moore tells us that he and his co-workers examined every possible empirical factor in the behavioristically con-

34. Northrop, The Logic of the Sciences and the Humanities, c. XIII (1947). 
ceived situation upon which this equation might depend. Two equations were discovered.

The first of these two equations defines the point at which the living law of the future state of the social system will begin to deviate from the living law of its present state. The second of the two equations defines the difference between the deviational part of the future state and the part of the earlier state from which the future state was a deviation. One has, therefore, but to examine these two equations in order to determine whether it is possible in social science, in sociology, and in the sociology of law to deduce the future state of the system from a present state.

Such an examination shows that the future state can be deduced only if one knows initially not merely the living law distribution of the present state of the social system but also the positive law norm which is to be introduced. Neither of the two equations relating the future state of the system to the present state can be solved unless the positive law norm of the future state is known initially. ${ }^{35}$ Thus instead of being able to deduce $\mathrm{LL}^{\prime}$ from $\mathrm{LL}^{\circ}$ and then being free to determine the new legal norm by merely writing out the propositions of $\mathrm{PL}^{\prime}$ in such a way that they correspond to $\mathrm{LL}^{\prime}$, Underhill Moore's research permitted only the deduction of $L L^{\prime}$ if one knew at the earlier time $t^{\circ}$, not merely $\mathrm{LL}^{\circ}$, but also $\mathrm{PL}^{\prime}$. Underhill Moore saw consequently that his research did not give the predictive power necessary for a handling of normative social and legal questions on a realistic sociological basis, even for the simple type of social system which he studied.

He knew nonetheless that he had used the most powerful methods for deriving law from sociology by the application of the methods of natural science to social facts which the entire armory of the weapons of natural science provides. He knew also that he had applied these most powerful methods faithfully to the simplest possible socio-legal system where if anywhere they should succeed. If these methods failed to give new normative legal and social theory in such a simple social situation, then the scientifically weaker natural history inductive methods of many of his colleagues who thought they were creating a new sociological jurisprudence capable of dealing with norms to succeed that of Underhill Moore must fail even more lamentably.

It is to be concluded, therefore, that Underhill Moore and his legal science will have to be reckoned with by all subsequent social scientists and legal thinkers. He has given the world its first experimentally verified, deductively formulated sociology of law. Thereby he has raised a legal realism and sociological jurisprudence to the greatest heights, both methodologically and predictively, of which they seem to be capable. This is the reason why he more than anyone else has shown what legal realism and sociological jurisprudence can and cannot do.

35. Moore \& Callahan, supra note 14, at Appendix E, pp. 130-2. 
Underhill Moore's legal science, therefore, has demonstrated the three following things concerning the capacity of a juristic science whose method is that prescribed by Ehrlich as "a science of observation" or, to put the matter more exactly, whose method is that of natural science applied to social facts:

First, it can give an objectively verified specification of the living law and the corresponding positive law norms of the present status quo. This is an exceedingly important achievement since it is as essential to have objective knowledge concerning the de facto inner social order and positive law norms unmixed with the speculative normative proposals of reformers as it is to have a trustworthy new normative theory.

Second, there is the possibility that, given an objective determination of the living law high frequency behavior of the present status quo and assuming a specific new positive law norm, one can determine (a) the point at which the introduction of this new norm will result in a change of future high frequency social behavior from that of the present, and (b) predict the amount of the deviation beyond this point. However, before this possibility becomes an actuality, the two equations discovered by Underhill Moore must be connected more definitely with the deductively formulated assumptions of his theory; also the equations must be shown to hold for new objective studies using different norms and different social practices from those of Underhill Moore's traffic and parking studies. It is very important that such new applications of his method be made.

Third, legal realism and sociological jurisprudence, even when implemented with the most powerful and objective scientific methods for determining changes of the inner order of society with time, are not capable of designating a new norm or of resolving normative legal and social disputes. The verbal, subjective, intuitive methods of the earlier legal theories, however, are shown by Underhill Moore's research to be even more untrustworthy. It follows, therefore, since the domestic and international problems of the contemporary world are inescapably and increasingly ideological and normative in character, that an adequate legal science, while retaining legal realism and sociological jurisprudence for the two aforementioned tasks for which they are competent, must go beyond both.

The direction which this advance must take is also clear. First, Underhill Moore's conception of a proposition in law as merely the bare particular stimulus or particular cue to a response must be modified to include the meaningfulness and efficacy in overt behavior of ideological factors as required by the neurological and behavioristic, scientific findings of Professors McCulloch, Pitts, Rosenblueth, Wiener and Bigelow and as applied to the role of ideological factors in human behavior and the resultant inner order of society by this writer. This change will have the effect of grounding law in a social science which places its emphasis upon the "logical-meaningful" relations determin- 
ing the inner order of society first indicated in the sociology of Professor Pitirim A. Sorokin ${ }^{36}$ and upon the key importance of the philosophical assumptions of any society as emphasized by many contemporary anthropologists such as Professor Clyde Kluckhohn. ${ }^{37}$ In short, the theory of the living law as well as the positive law will be grounded in the science and philosophy of the world's cultures. ${ }^{38}$ Such a legal science offers the first constructive approach to a new international law which will be effective because it has taken into account the many underlying living laws of the different peoples, cultures and nations of the world. It also offers the first clear envisagement of the problem involved in even domestic disputes where a conflict of laws is present. If not supplemented by other novel methods, however, it will leave scientific jurisprudence confronted with a diversity of living law and corresponding positive law norms, some of which, at least, conflict because they are mutually incompatible. ${ }^{39}$ It will enable us to formulate ideological, legal and social problems but it will not provide a method for resolving them.

To resolve such problems some method in legal science is required which supplements the aforementioned method of the science and philosophy of the world's cultures. Underhill Moore's legal science has demonstrated that this method is not to be found in a scientific study of society or culture. This being the case, only one other source remains-namely, nature and the philosophy entailed in the verified theories of the contemporary science of nature. The increasing role of the technological consequences of the verified theory of natural science, such as the release of atomic energy, in outmoding the traditional living law practices and their corresponding positive law norms supports this conclusion. Such developments make it evident that adequate new legal and social norms must take into account man's contemporary knowledge of nature and its philosophical assumptions and implications, as well as his contemporary knowledge of the world's societies and their diverse philosophies of culture. It appears, therefore, that the legal science of the immediate future must draw upon the contemporary philosophy of the social sciences for its statement and clarification of the ideological legal and social problems of our time and turn to the philosophy of experimentally verified natural science for a designation of new social and legal norms or for a resolution of disputes involving differences or conflicts between traditional norms.

36. Sorokin, Sctence, Culture and Personality: Therr Structure and DynamICs, 42-63, 317-24, 337-40, 635-8 (1947).

37. Kluckhohn, supra note 24 , at 356 .

38. Northrop, Jurisprudence in the Law School Curriculum, 1 J. LEg. Ed. 482 (1949); Northrop, The Logic of the Sciences and the Humanities, c. XXI (1947).

39. Pound, supra note 24 ; Northrop, The Meeting of East and West, c. XII (1946) ; Northrop, The Logic of the Sciences and the Humanities, cc. XVIII, XX (1947). 